\title{
Study of the Assembly Manufacturing Automated Traceability System Identification Tools
}

\author{
Vladimir Nosenko ${ }^{1}$, Aleksei Silaev ${ }^{1 *}$, Stepan Efremkin ${ }^{1}$, and Sergei Grednikov ${ }^{2}$ \\ ${ }^{1}$ Volzhsky Polytechnic Institute (Branch) of the Volgograd State Technical University, 404121 \\ Volzhsky, 42A Engelsa str. Russian Federation \\ ${ }^{2}$ The limited liability company "Volgopromavtomatika", 404131 Volzhsky, Mira st. 53b, the Russian \\ Federation
}

\begin{abstract}
This paper considered questions of quality control of production at assembly manufacturing using an automated traceability and identification system. The main possibilities of these systems are: control of the movement of materials, components and products within the production; construction the technological route and control over the accuracy of its compliance; identification all operations with a binding to the operators. Also authors are carried out the review of problems that can be solved by these systems. As one of the methods of identification of materials, components and products, the technology of using RFID-tags are considered. The main characteristics of RFID tags have analyzed (frequency of work, design, power supply). Advantages and disadvantages of this technology are revealed. For example, advantages are high protection at hard operating conditions, rewritable tags and the disadvantages are limited using the tags at high temperatures, occurrence the effect of collision. Authors made conclusions that investigated RFIDtags can be used for assembly manufacturing.
\end{abstract}

\section{Introduction}

Quality control of products in manufacturing in full is possible only with the use of the automated system of identification and traceability of products (ASITP). Such technologies are particularly effective for assembly plants, where the account of a large number of materials and components in all technological and controlled operations are the key factor to improve the efficiency of the organization and production planning.

Identification and traceability system is an automated system that allows to collect, control and analyze information about technological operations, personnel and resources involved in the production process [Ошибка! Источник ссылки не найден.].

Identification is carried out by applying a special marking on the product in accordance with the design and technological documentation, indicating all the necessary characteristics of the product, affecting its quality and necessarily a unique number.

*Corresponding author: aa_silaev@mail.ru 
Traceability of products is the process of preparation of technological documentation, which is a process of recording technological and control operations, indicating the detected defects and measures taken to eliminate them [1].

Key capabilities of the ASITP are as follows:

- control over the materials, components and products movement within the production;

- construction of the technological route and control over the accuracy of compliance therewith;

- identification of all operations and linking them to the operators;

- accounting of the actual time required for operations and the whole process;

- integration with the ERP and other systems of the enterprise.

There are two types of traceability:

- internal traceability (within the shop or enterprise);

- chain traceability (full traceability from raw materials to finished products)

\section{[Ошибка! Источник ссылки не найден.].}

It is obvious that the effectiveness of the traceability system depends on the technical implementation of methods for identifying materials, components and products in general.

One of the promising methods of identification is the use of RFID technology, the meaning of which is to apply special electronic RFID-tags that allow to obtain the required information over a wireless network. A variety of form factors of such tags gives the possibility of using the studied technologies in many industries. The use of RFID technology allows multiple reading of information from identifiers through non-metallic barriers (conveyor belts, walls of boxes and containers, walls of buildings) [4], and also provides the ability to embed the identifier directly into the object (for example, inside a plastic part when casting it). This makes it the most promising way to obtain the required data at the stages of goods manufacturing.

Thus, the purpose of the article is to study the identification tools necessary to build an automated system. The objectives are the study of scientific and technical literature, analysis of examples of the use of RFID technology, determining the advantages and disadvantages of using RFID technology.

\section{Review of theoretical studies}

At this stage of industry development, the problem of identification of materials for creation of products is of high interest. Numerous enterprises have implemented a system of tracking raw materials, components or assembly units which needs improvements only tests the finished product, which entails defects missing at an intermediate stage, an increase in the consumption of components, lack of efficiency in obtaining information and other shortcomings in operations stipulated by the technological regulations.

The introduction of the identification and tracing system in the existing processes is a promising direction in the development of the industry. It may provide full information on a product and its movement that allows to exclude falsification and to reduce costs of re-issue of products in the case of detecting defects in a batch [5].

The use of RFID technology allows solving the problem of inventory, quality management of raw materials/materials/components, and also leads to improved production planning, by reducing downtime and other conditions [6]. RFID (Radio Frequency IDentification) - a method of automatic identification of objects in by way of which radio signals, data stored in the so-called transponders, or RFID-sensor are read or recorded [8]. One of the main elements of this technology is a tag, i.e. a data carrier, which stores the information requested by the reading/polling device by modulating the magnetic field or the 
carrying frequency of the emitted electromagnetic field for its subsequent transmission to the information system [9]. Currently, there is a wide variety of tag types, and the principal classification is given below:

1. By frequency of operation (high frequency (13.56 MHz); ultra-high frequency (860-960 MHz);

2. $\quad$ By form (tags, body-affixed, special);

3. By power source (active, passive, semi-active)

Along with the variety of possible tags, there is a classification of RFID readers, which are usually divided into mobile and stationary readers [11]. Mobile ones are mainly used for manual control of products, use in warehouses, reducing unauthorized access of personnel to operator rooms, etc. Stationary readers are designed for reading RFID tags directly during the process and are characterized by maximum speed and range of registration. Depending on the requirements, there are portal, ceiling and tunnel RFID readers.

Implementation of the technology involves the division of the production line into zones, in each of which a certain set of production operations is performed. Each product has a unique identifier (RFID tag) recorded by the RFID reader when the product enters the next zone. The possible routes of the products are predefined in the system settings.

The table provides a comparative analysis of RFID tag technology, which takes into account the following factors: tag type, frequency range, operating temperature, application scope, affixing method, protection from external factors, cost. Data was collected from RFID technology information source [12]. The analysis shows that the production tags have approximately the same values of operating temperature, operating frequency ranges, as well as the degree of protection.

Table 1.

\begin{tabular}{|l|l|l|l|l|}
\hline \multicolumn{1}{|c|}{ Tag name } & $\begin{array}{c}\text { Confidex } \\
\text { Ironside Micro } \\
\text { Global 3000448 }\end{array}$ & $\begin{array}{c}\text { TTF Flexible } \\
\text { Laundry 321V1 }\end{array}$ & $\begin{array}{l}\text { Xerafy Roswell } \\
\text { w/ Bracket EU } \\
\text { X1114-EU101- } \\
\text { H3 }\end{array}$ & Intermec IT66 \\
\hline Tag type & Passive & Passive & Passive & Passive \\
\hline Frequency range & $865-928 \mathrm{MHz}$ & $860-928 \mathrm{MHz}$ & $866-868 \mathrm{MHz}$ & $860-930 \mathrm{MHz}$ \\
\hline $\begin{array}{l}\text { Operating } \\
\text { temperature }\end{array}$ & $-35^{\circ} \mathrm{C}-+85^{\circ} \mathrm{C}$ & $-40^{\circ} \mathrm{C}-+85^{\circ} \mathrm{C}$ & $-40^{\circ} \mathrm{C}-+85^{\circ} \mathrm{C}$ & $\begin{array}{l}-40^{\circ} \mathrm{C} \\
+121^{\circ} \mathrm{C}\end{array}$ \\
\hline $\begin{array}{l}\text { Application } \\
\text { scope }\end{array}$ & $\begin{array}{l}\text { Marking of } \\
\text { containers, metal } \\
\text { products }\end{array}$ & $\begin{array}{l}\text { Marking of } \\
\text { textile products }\end{array}$ & $\begin{array}{l}\text { Marking of metal } \\
\text { products }\end{array}$ & $\begin{array}{l}\text { Marking of } \\
\text { plastic, metal, } \\
\text { wood products }\end{array}$ \\
\hline Affixing method & $\begin{array}{l}\text { Opening for a tag } \\
\text { Protection from } \\
\text { external factors }\end{array}$ & $\begin{array}{l}\text { IP68; } \\
\text { Protection against } \\
\text { the effects of } \\
\text { chemically } \\
\text { aggressive media }\end{array}$ & IP67 & $\begin{array}{l}\text { Two screw bores } \\
\text { Adhesive base; } \\
\text { bolts etc. }\end{array}$ \\
\hline Cost (piece) & 161 rubles & 244 rubles & $\begin{array}{l}\text { Protection against } \\
\text { theffects of } \\
\text { chemically } \\
\text { aggressive media }\end{array}$ & IP67 rubles \\
\hline
\end{tabular}

Another equally important parameter for designing the identification system based on RFID tags is the tag reading distance (Fig.). 


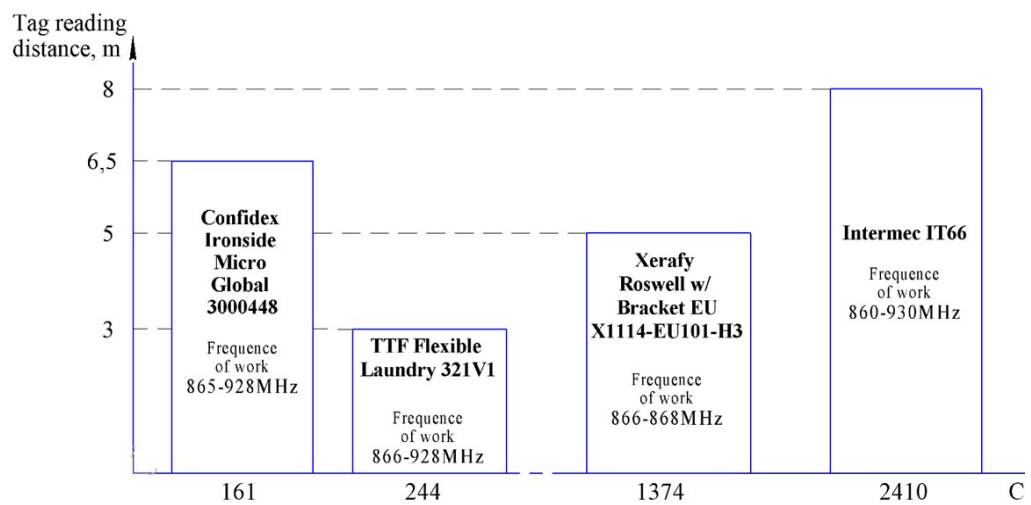

Fig. 1. Relative cost and tag reading distance.

\section{Results and discussion}

Based on the information presented in the graph, we can assume that the tags with a higher cost do not always have a greater potential for use compared to cheaper counterparts.

It is also necessary to emphasize that the labels analyzed are highly independent of operating conditions (gases, dust, dirt, vibration, water, light, etc.). This makes it possible to use this identification tool in most industrial enterprises.

Another advantage is the ability of some RFID tags to be rewritable (Read/Writing). There is an extensive class of tasks where additional information needs to be placed in the label. In this case, rewritable identifiers with additional non-volatile memory are used, in which information is stored after the power supply is turned off.

The undoubted advantage of modern RFID tags is their "passivity", since these tags operate without a power source [13] receiving power from the reader signal. Passive tags are smaller and lighter than active tags, less expensive, have a virtually unlimited service life.

But it is also considered a disadvantage, as the passivity assumes the tag operability only at the moment when it receives a signal from the receiver [14]. Thus, the rest of the time the identifier "passively" reacts to disturbances arising both from the inside and outside. This fact highlights the impossibility of using tags to track the value of process parameters in dynamically changing processes.

It should be noted that the considered tags can be used only at the stage of assembly manufacturing or transportation of products, since most models have an operating temperature range limited to $+85^{\circ} \mathrm{C}$, which indicates the impossibility of tracking products at stages with higher temperatures.

Another drawback may be the effect of conflict [15] which arises due to the location of several identifiers in the field of view of one reader. In order to avoid such situations, it is reasonable to develop an anti-collision mechanism designed to enable the reader to determine all the tags by their unique serial numbers, and then alternate processing of the information received.

\section{Conclusion}

Identification of materials, components and products using RFID-tags is a promising direction for traceability organization in manufacture. Studies have shown that modern RFID tags are able to operate at distances up to tens of meters, and radio waves can read the 
signal, including through non-metallic barriers, which allows them to be used in the assembly and conveyor manufacturing processes. At the same time, the operating temperature of the tags is sufficient for many assembly plants. This means that the received technical solutions may be applied in various fields of mechanical engineering and other areas where control, which can be carried out by means of RFID technologies is necessary. The tag remains on the finished product for the entire period of its operation, which facilitates the procedure of accounting and maintenance.

\section{References}

1. R. Ginley, 2015 IEEE 16th Annual Wireless and Microwave Technology Conference, Traceability for microwave power measurements: Past, present, and future (13-15 April 2015)

2. BSR, United Nations Global Compact Office, A Guide to Traceability: A Practical Approach to Advance Sustainability in Global Supply Chains (2014)

3. Traceability Textbook, Technical Guide, (2019)

4. S. Sanjay, ACM New York Queue, 2:2, 50 (2004)

5. S. E. Vasileva, R. K. Kraineva, ANI: Economics and management, 4, 83 (2016)

6. R. Durick, Beyond track-and-trace: Using RFID on the factory floor, Applied Automation supplement to Control Engineering and Plant Engineering (February, 2013)

7. S. Williams, M. Taylor, A. Mehta, I. Jeffrey, The National Institute of Standards and Technology, NISTIR 8030 (November 2014)

8. Z. Junfang, L, Ran, L. Jin, L, Yu, Journal of Systems Engineering and Electronics, 20:3, 577 (June 2009 )

9. GOST R ISO/IEC 15963-2011. Information technology. Radio frequency identification for item management (Moscow, 2011)

10. T. Hoske, M. Identify the right RFID technology: Knowing the difference between HF and UHF is important for industrial applications

11. A. Jedda, H. Mouftah, IEEE Transactions on Emerging Topics in Computing, 4:4, 502 (Oct.-Dec. 2016)

12. Project RFID expert: guide to RFID technology

13. H. Niu, S. Jagannathan, 39th Annual IEEE Conference on Local Computer Networks (8-11 Sept. 2014)

14. H. Yang, S.H. Yang, Institute of Measurement and Control, 40:2, 56 (2007)

15. N. Jeevagan, P. Santosh, R. Berlia, S. Kandoi, IEEE Global Humanitarian Technology Conference, RFID based vehicle identification during collisions (December 2014) 